This journal provides immediate open access to its content under the Creative Commons BY 4.0 license. Authors who publish with this journal retain all copyrights and agree to the terms of the above-mentioned CC BY 4.0 license.

DOI: $10.2478 /$ seeur-2020-0007

\title{
A STUDY ON COMPARATIVE ANALYSIS OF COVID-19 DATASETS
}

PhD. Cand. Genc Hamzaj

Faculty of Contemporary Sciences and Technologies, South East European University,

Tetovo, North Macedonia

genc.hamzaj85@gmail.com

Prof. Dr. Zamir Dika

Faculty of Contemporary Sciences and Technologies, South East European University,

Tetovo, North Macedonia

z.dika@seeu.edu.mk

Prof. Assoc. Dr. Isak Shabani

Faculty of Electrical and Computer Engineering, University of Prishtina "Hasan Prishtina",

Prishtina, Kosovo

isak.shabani@uni-pr.edu

\begin{abstract}
In December 2019 a virus named COVID-19 appeared in China, precisely in the city of Wuhan. This virus was declared a global pandemic by the World Health Organization in March 2020. Since no adequate medical treatment has yet been discovered for this virus, many world institutions are committed to share with each other the data they collect and process in their laboratories. A large amount of these data is shared with citizens in order to inform about the risk that threaten us by virus COVID-19.

Various credible world institutions such as the World Health Organization (WHO), Johns Hopkins University (JHU), the European Centre for Disease Prevention and Control (ECDC), etc., are providing various statistical data to address the issues raised by this emergent situation, but these reports in some cases are putting doubts on the completeness and the transparency of
\end{abstract}


the data, which are not sufficiently processed and which then create confusion about the risks that we are facing.

In this paper we are conducting a study of the quality of current global datasets from the must credible sources related to COVID-19. Also, we are comparing datasets collected from Republic of Kosovo and Republic of North Macedonia with corresponding data from WHO, ECDC and JHU datasets.

To analyze datasets from different sources, we are using Power BI tool, making the improvement through the implementation of adequate dimensions and methods of improving the quality of datasets.

Key words: COVID-19, Datasets, Data Dimensions, Open Data.

\section{INTRODUCTION}

From the first case reported of COVID-19 coronavirus in Wuhan until August 22, 2020, the virus has spread to a total of 213 countries with a total of over 23 million cases and over 800 thousand deaths [1]. Global cooperation and coordination are essential to overcome this challenge. Consistent recording of COVID-19 related information is critically important to understand transmissibility, risk of geographic spreading, routes of transmission, and risk factors for infection [2]. Government institutions, researchers, public health authorities and other stakeholders will benefit from reliable and accurate data. All these data are needed to evaluate the impact of the Coronavirus pandemic on health care systems for better planning and for an appropriate policy response. In this situation, high-quality institutional-based datasets are the prerequisite of necessary analysis for public health and other public institutions, which is inherently a data-intensive domain [3].

Data quality assessment and data visualization are very important processes in understanding data. Data quality itself is a multidimensional concept with dimensions such as, accuracy, completeness, relevancy, timeliness, etc. There are frameworks for data quality assessment that are motivated by what data quality means to the consumers of data. Although there is an overlap between quality of data and quality of data reporting, they are not quite the same. Accuracy is a crucial aspect in data quality. However, while measuring the quality of data reporting, the emphasis is not on the accuracy of data, instead it is on the presence or absence of a piece of information and the format in which it is reported [4]. Visualization is critical for understanding 
data. By using adequate statistical graphics, we communicate complex ideas with clarity, precision, and efficiency. Through this paper we will present the process of collecting, integrating, comparing, assessing and visualizing COVID-19 related datasets, using as the reference datasets from World Health Organization (WHO), John Hopkins University (JHU), and European Centre for Disease Prevention and Control (ECDC). We also will present the process of comparing datasets collected from Republic of Kosovo and Republic of North Macedonia with corresponding data from WHO, ECDC and JHU datasets.

The paper is organized as follows: We first overview official COVID-19 datasets like the World Health Organization (WHO), John Hopkins University (JHU) and the European Centre for Disease Prevention and Control dataset (ECDC). In Methodology we will specify the way of collecting, assessing, improving and visualizing the data of these datasets. In a specific section we will compare data collected from official health institution web portals of Republic of Kosovo and Republic of North Macedonia with the data that are present in the datasets of WHO, JHU and ECDC for these two countries. In Results we will present the outcomes from this paper. The paper finishes with the Conclusion.

\section{DATASETS ANALYTICS}

The data used in this study are from the repositories of the World Health Organization (WHO), the European Centre for Disease Prevention and Control (ECDC), John Hopkins University (JHU), the Republic of North Macedonia and the Republic of Kosovo official COVID-19 data.

\section{WORLD HEALTH ORGANIZATION (WHO) DATASET}

The World Health Organization (WHO) has been in regular and direct contact with all national authorities in all countries since the reporting of their COVID-19 cases. The report is organized on daily bases including the raw data and the metadata. At the beginning, data were reported in a pdf format but now these data are in Microsoft Excel and CSV format, mostly with the aim to represent the numbers and inform the developments of public health policies such as quarantine and the establishment of priorities such as urgent research for implementing surveillance of this new disease [5]. The structure of pdf files was not similar, and the number of tables was not fixed. Therefore, at the beginning it was difficult to read these data fully automatically, and it was needed to interfere manually to adjust the data several times. 
Nowadays, the datasets are mostly in Microsoft Excel and CSV formats which simplifies the process of analyzing, improving and visualizing the data.

A sample of dataset from the World Health Organization is shown in following table:

\begin{tabular}{|l|l|l|l|l|l|l|l|}
\hline Date reported & $\begin{array}{l}\text { Country } \\
\text { code }\end{array}$ & Country & $\begin{array}{l}\text { WHO } \\
\text { region }\end{array}$ & $\begin{array}{l}\text { New } \\
\text { cases }\end{array}$ & $\begin{array}{l}\text { Cumulative } \\
\text { cases }\end{array}$ & New deaths & $\begin{array}{l}\text { Cumulative } \\
\text { deaths }\end{array}$ \\
\hline $3 / 11 / 2020$ & AF & Afghanistan & EMRO & 3 & 11 & 0 & 0 \\
\hline $8 / 27 / 2020$ & AF & Afghanistan & EMRO & 55 & 38126 & 4 & 1401 \\
\hline $3 / 9 / 2020$ & AL & Albania & EURO & 6 & 6 & 0 & 0 \\
\hline $8 / 24 / 2020$ & AL & Albania & EURO & 152 & 8427 & 5 & 250 \\
\hline $1 / 4 / 2020$ & CN & China & WPRO & 1 & 1 & 0 & 0 \\
\hline $8 / 24 / 2020$ & CN & China & WPRO & 41 & 90182 & 1 & 4718 \\
\hline $1 / 29 / 2020$ & IT & Italy & EURO & 6 & 6 & 0 & 0 \\
\hline $8 / 24 / 2020$ & IT & Italy & EURO & 1209 & 259345 & 7 & 35437 \\
\hline $3 / 13 / 2020$ & XK & Kosovo[1] & EURO & 6 & 6 & 0 & 0 \\
\hline $8 / 24 / 2020$ & XK & Kosovo[1] & EURO & 111 & 12405 & 10 & 457 \\
\hline $2 / 26 / 2020$ & MK & North Macedonia & EURO & 5 & 5 & 0 & 0 \\
\hline $8 / 24 / 2020$ & MK & North Macedonia & EURO & 287 & 13595 & 7 & 564 \\
\hline$\ldots$ & $\ldots$ & $\ldots$ & $\ldots$ & $\ldots$ & $\ldots$ & $\ldots$ & $\ldots$ \\
\hline $3 / 20 / 2020$ & ZW & Zimbabwe & AFRO & 1 & 1 & 0 & 0 \\
\hline $8 / 24 / 2020$ & ZW & Zimbabwe & AFRO & 37 & 5930 & 2 & 155 \\
\hline
\end{tabular}

A dashboard from the World Health Organization is shown in Figure 1.

Situation by WHO Region

Americas
Europe
South-East Asia
Eastern Mediterranean
Western Pacific
Source: World Heath organization
Wh Data may be incomplete tor the ourrent day or week.

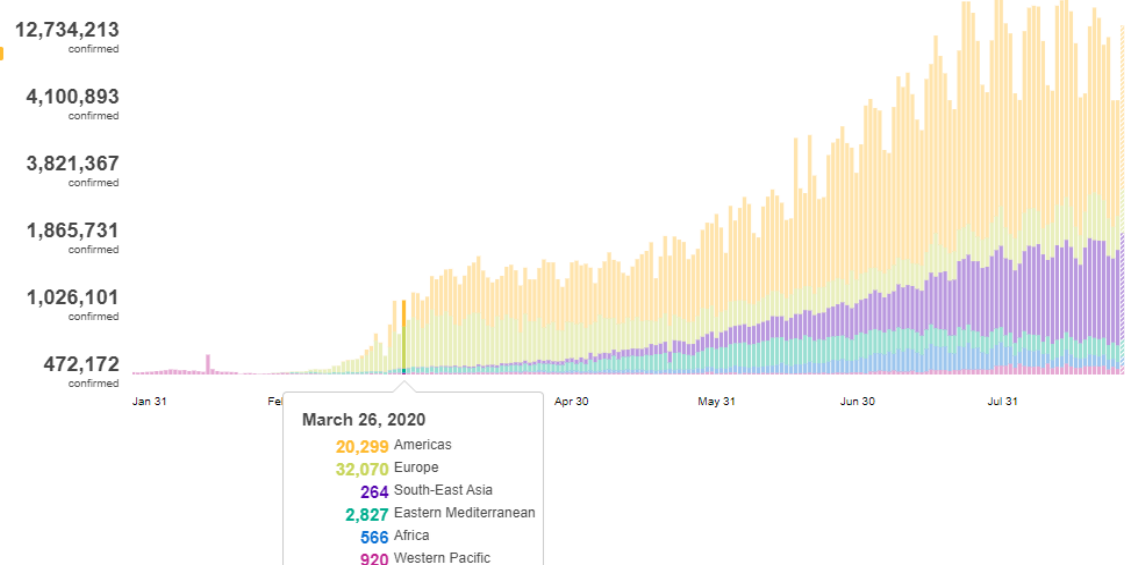

Figure 1. A sample of dataset from World Health Organization.

\section{THE EUROPEAN CENTRE FOR DISEASE PREVENTION AND \\ CONTROL (ECDC) DATASET}


In ECDC's website [6] datasets are available in CSV, JSON and XML format about COVID19 with field names as shown in the table below. Datasets are daily updated and contain the latest available public data on COVID-19. To ensure the accuracy and reliability of the data, this process is being constantly refined. This helps to monitor and interpret the dynamics of the COVID-19 pandemic not only in the European Union (EU), the European Economic Area (EEA), but also worldwide.

The details of ECDC dataset are in the following table:

\begin{tabular}{|l|l|l|l|l|l|l|l|}
\hline ISO code & Continent & Location & Date & total cases & new cases & $\begin{array}{l}\text { total } \\
\text { deaths }\end{array}$ & $\begin{array}{l}\text { new } \\
\text { deaths }\end{array}$ \\
\hline BEL & Europe & Belgium & $2020-03-11$ & 601 & 99 & 1 & 1 \\
\hline BEL & Europe & Belgium & $2020-08-27$ & 82936 & 0 & 9879 & 1 \\
\hline BRA & South America & Brazil & $2020-03-18$ & 291 & 57 & 1 & 1 \\
\hline BRA & South America & Brazil & $2020-08-27$ & 3717156 & 47161 & 117665 & 1085 \\
\hline DEU & Europe & Germany & $2020-01-28$ & 1 & 1 & 0 & 0 \\
\hline DEU & Europe & Germany & $2020-08-27$ & 237936 & 1507 & 9285 & 5 \\
\hline OWID_KOS & Europe & Kosovo & $2020-03-14$ & 2 & 2 & 0 & 0 \\
\hline OWID_KOS & Europe & Kosovo & $2020-08-27$ & 12683 & 0 & 488 & 0 \\
\hline MKD & Europe & Macedonia & $2020-03-07$ & 3 & 2 & 0 & 0 \\
\hline MKD & Europe & Macedonia & $2020-08-27$ & 13799 & 126 & 573 & 5 \\
\hline$\ldots$ & $\ldots$ & $\ldots$ & $\ldots$ & $\ldots$ & $\ldots$ & $\ldots$ & $\ldots$ \\
\hline ZWE & Africa & Zimbabwe & $2020-03-21$ & 1 & 1 & 0 & 0 \\
\hline ZWE & Africa & Zimbabwe & $2020-08-27$ & 6251 & 55 & 179 & 13 \\
\hline
\end{tabular}

\section{JOHNS HOPKINS UNIVERSITY (JHU) DATASET}

The Johns Hopkins Coronavirus Resource Center (CRC) is a continuously updated source of COVID-19 data and expert guidance. They aggregate and analyze the best data available on COVID-19-including cases, as well as testing, contact tracing and vaccine efforts - to help the public, policymakers and healthcare professionals worldwide respond to the pandemic [7]. JHU provides a daily update of the global map of the pandemic, which are in CSV format.

The details of JHU dataset are in the following table:

\begin{tabular}{|l|l|l|l|l|l|l|l|l|}
\hline Province/State & Country/Region & Lat & Long & $1 / 22 / 20$ & $1 / 23 / 20$ & $\ldots$ & $8 / 22 / 20$ & $8 / 23 / 20$ \\
\hline & Afghanistan & 33.93911 & 67.709953 & 0 & 0 & $\cdots$ & 37953 & 37999 \\
\hline & Albania & 41.1533 & 20.1683 & 0 & 0 & $\cdots$ & 8275 & 8427 \\
\hline Queensland & Australia & -27.4698 & 153.0251 & 0 & 0 & $\cdots$ & 1105 & 1106 \\
\hline Tasmania & Australia & -42.8821 & 147.3272 & 0 & 0 & $\cdots$ & 230 & 230 \\
\hline
\end{tabular}




\begin{tabular}{|l|l|l|l|l|l|l|l|l|}
\hline Victoria & Australia & -37.8136 & 144.9631 & 0 & 0 & $\ldots$ & 18231 & 18330 \\
\hline & Belgium & 50.8333 & 4.469936 & 0 & 0 & $\ldots$ & 81468 & 81936 \\
\hline & Japan & 36.204824 & 138.252924 & 2 & 2 & $\ldots$ & 61916 & 62658 \\
\hline & Kosovo & 42.602636 & 20.902977 & 0 & 0 & $\ldots$ & 12168 & 12448 \\
\hline & North Macedonia & 41.6086 & 21.7453 & 0 & 0 & $\ldots$ & 13458 & 13595 \\
\hline
\end{tabular}

A dashboard from JHU for COVID-19 dataset is shown in Figure 2.

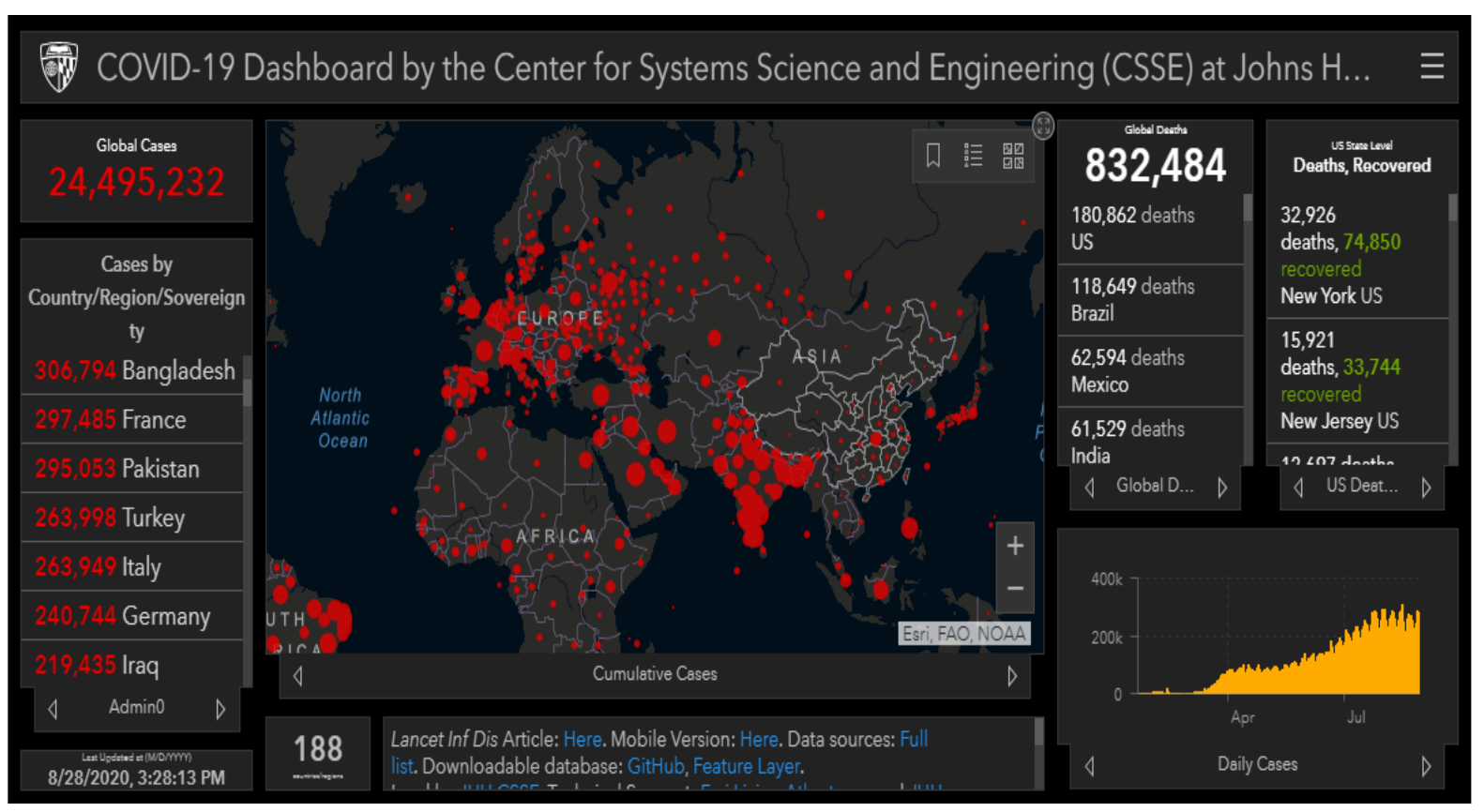

Figure 2. Dashboard from JHU for COVID-19 dataset

\section{REPUBLIC OF KOSOVO DATASET}

The National Institute of Public Health of Kosovo (NIPHK) publishes the results every day on its Facebook page [7]. The data is published as an image i.e. not published in a format that can be used for further analysis like CSV XML etc. The institute presents every day the number of new cases with COVID-19, the number of deaths and the number of recovered. Also, the cumulative values of new cases, cases of deaths and cases of the healed are calculated in daily bases.

The details of NIPHK data are in the following table:

\begin{tabular}{|l|l|l|}
\hline COVID-19 cases by municipalities & Locality & Number of cases \\
\hline Deçan, total: 2 , by localities & Deçan & 1 \\
\hline & Strellc i Ulët & 1 \\
\hline
\end{tabular}




\begin{tabular}{|l|l|l|}
\hline Gjakovë, total: 19, by localities & Gjakovë & 14 \\
\hline & Rogovë & 1 \\
\hline & Skivjan & 3 \\
\hline & Stubëll & 1 \\
\hline Prishtinë, total: 23 , by localities & Prishtinë & 20 \\
\hline & Hajvali & 2 \\
\hline & Matiçan & 1 \\
\hline Prizren, total: 6, by localities & Prizren & 6 \\
\hline$\ldots \ldots$ & $\ldots .$. & $\ldots$. \\
\hline In total & 25 municipalities & 141 \\
\hline
\end{tabular}

\section{REPUBLIC OF NORTH MACEDONIA DATASET}

The Government of the Republic of North Macedonia (GRNM) on its web portal publishes the results of the COVID-19 cases [8]. The data are published in a tabular form and can be exported in various formats such as CSV, etc., for further analysis.

The details of the dataset taken from GRNM are in the following table:

\begin{tabular}{|l|l|l|l|}
\hline Date & Sick & Healed & Death in total \\
\hline 5 -Mar-20 & 1 & 0 & 0 \\
\hline 6 -Mar-20 & 2 & 0 & 0 \\
\hline$\ldots$ & $\ldots$ & $\ldots$ & $\ldots$ \\
\hline $1-$ Apr-20 & 354 & 17 & 11 \\
\hline 2 -Apr-20 & 384 & 17 & 11 \\
\hline$\ldots$ & $\ldots$ & $\ldots$ & $\ldots$ \\
\hline 1 -Aug-20 & 10900 & 6698 & 493 \\
\hline 2-Aug-20 & 11066 & 6883 & 497 \\
\hline$\ldots$ & $\ldots$ & $\ldots$ & $\ldots$ \\
\hline 23-Aug-20 & 13592 & 10405 & 567 \\
\hline
\end{tabular}




\section{METHODOLOGY}

Initially, these three global datasets had to be converted into an appropriate and analogous form, and then start the process of analyzing and comparing each other. This was necessary because at the JHU dataset, data of reported cases and deaths are presented in columns while in the other datasets they are presented in rows. The alpha- 2 codes were added to all rows of these datasets, combined with the Date variable for each row to make a unique primary key for each country and each day. This primary key was used to combine these three datasets into one.

A Joint Datasets Table of the combined data sources is shown in following table:

\begin{tabular}{|c|c|c|}
\hline Attribute & Description & Additional information \\
\hline Row_ID & ID of row & Unique ID of data \\
\hline Date & Date of reported Cases and Deaths & Date in ddmmyyyy format \\
\hline Continent & Continent where the country exists & \\
\hline Area & WHO Region & $\begin{array}{l}\text { The World Health Organization divides the world into six } \\
\text { WHO regions, for the purpose of reporting, analysis and } \\
\text { administration. }\end{array}$ \\
\hline Country & Name of country & Name of countries based on WHO reports. \\
\hline Alpha-2 & $\begin{array}{l}\text { Abbreviation code of the country - } \\
\text { Two letters }\end{array}$ & Includes two letters for each country \\
\hline Alpha-3 & $\begin{array}{l}\text { Abbreviation code of the country - } \\
\text { Three letters }\end{array}$ & Includes three letters for each country \\
\hline latitude & Latitude of the country & \\
\hline longitude & Longitude of the country & \\
\hline WHO_TCC & WHO Total confirmed cases & $\begin{array}{l}\text { Total confirmed cases are the cumulative of confirmed } \\
\text { cases during the time, from WHO reports }\end{array}$ \\
\hline WHO_TD & WHO Total deaths & Cumulative aggregation of deaths in WHO reports. \\
\hline JHU_TCC & JHU Total confirmed cases & $\begin{array}{l}\text { Total confirmed cases are the cumulative of confirmed } \\
\text { cases during the time, from JHU dataset }\end{array}$ \\
\hline JHU_TD & JHU Total deaths & Cumulative aggregation of deaths in JHU dataset \\
\hline ECDC_TCC & ECDC Total confirmed cases & $\begin{array}{l}\text { Total confirmed cases are the cumulative of confirmed } \\
\text { cases during the time, from ECDC dataset. }\end{array}$ \\
\hline ECDC_TD & ECDC Total deaths & Cumulative aggregation of deaths in ECDC dataset \\
\hline
\end{tabular}

\section{ABNORMAL DATA DETECTION}

During the period of analyzing datasets, data anomalies that were encountered include:

1. Negative numbers;

2. Order dependencies violation;

3. Delayed-reported issue on weekend/holiday;

4. Abnormal data point or data period;

These data anomalies must be cleaned and repaired in order to have credible data. 


\section{NEGATIVE NUMBERS}

Negative numbers should not exist in datasets because the count of confirmed cases or deaths for a certain date should naturally be zero or other positive numbers, so datasets should be cleaned from negative numbers.

\section{ORDER DEPENDENCIES VIOLATION}

Order dependency (OD) is widely used in the relational database. In this paper, we incorporate this concept into the abnormal data detection and data repairing process of cumulative time series. To be more specific, OD for the cumulative time series can be defined as follows: for any two time points, $\mathrm{t} 1$ and $\mathrm{t} 2$, if $\mathrm{t} 1<\mathrm{t} 2$, then $\mathrm{Yt} 1 \leq \mathrm{Yt} 2$, where $\mathrm{Y}$ represents the cumulative infectious/death count [8].

\section{WEEKEND/HOLIDAY DELAY-REPORTED ISSUE}

Weekend/holiday delay-reported issue refers to the situation when significantly fewer daily new cases are reported on weekends, holidays and/or the days before and after those days.

\section{ABNORMAL DATA POINT OR DATA PERIOD}

A single abnormal point refers to the situation where there is one day of an abrupt increase in the cumulative time series. This can have multiple causes like:

1. The result of a large batch of tests was released;

2. The change of reporting standard, e.g., some states started to report probable cases from a specific date.

Sometimes, we may experience a continuous abnormal period, referred to as the period where the increasing speed is significantly different from the previous and the subsequent period.

The general data curation workflow has been illustrated in figure 3 [9]. Once raw data is collected, the curation starts with the OD violation detection and repairing. The next step is the check for delay-reported issues on the weekend/holiday. Finally, checking for the abnormal data point and data period occurs. 


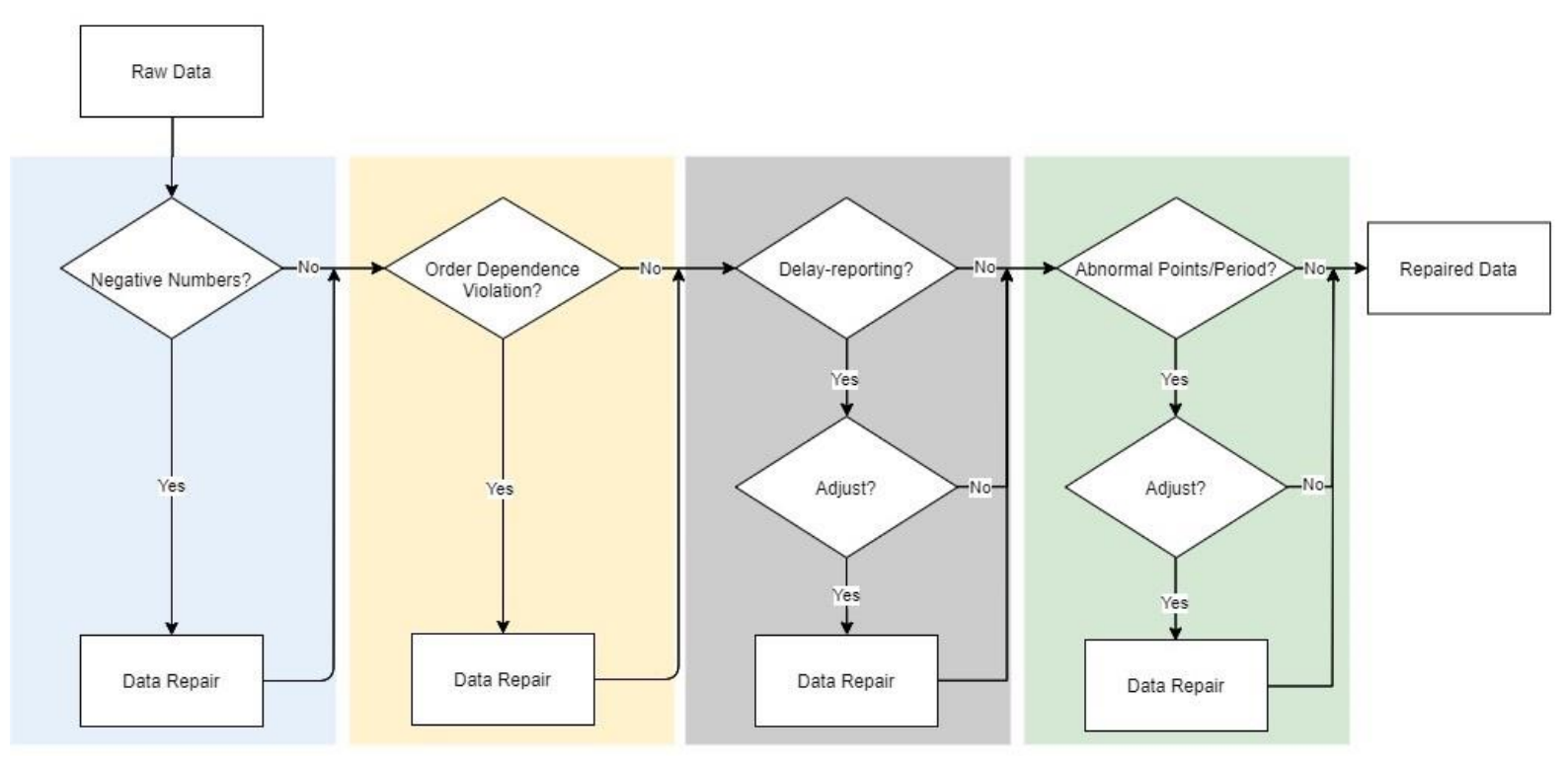

Figure 3. Data curation flowchart

COVID-19 data present the unique data quality challenges due to the spread of the virus globally and the problem of delayed-reporting and under-reporting [10]. The detection of abnormal data explores the level of poor data quality, to be followed by the cleaning of problematic data.

The data cleaning procedure is divided into two categories:

1. Manual cleaning; and

2. Automatic cleaning.

On the one hand, manual cleaning has very high accuracy; on the other hand, it is challenging to implement due to the high cost in time and effort.

In this paper, we have used Power BI software to analyze collected data from these datasets and visualize comparative results for cumulative cases and deaths. Our methodology consists in creating descriptive models of the coronavirus outbreak using statistical charts to understand the nature of the spread and its impact.

\section{RESULTS}

Using Power BI software, we collected and analyzed the data from these datasets and visualized comparative results about the cumulative cases and deaths. 


\section{NEGATIVE NUMBERS}

First, we checked datasets for negative numbers and we discovered some negative values in the attributes of new confirmed cases and new deaths, which are then corrected in order to eliminate abnormal data.

Also, the date variable and corresponding values in the three datasets was checked and it was determined that the values of this variable suffer from a one-day lag between the different datasets as follows: The WHO reports were initiated on 21 January 2020 and, as mentioned, in the first report that date refers to the occurrences on 20 January. Subsequently, the 22 January report communicated the 21 January statistics. However, in the 23 January report, the date as reported was also 23 January and included the information reported to the WHO Geneva at 10 AM CET. It means that the WHO has no data for 22 January, or it is aggregated with the data for the 23 January. This indicates that the WHO daily situation reports were shifted forward for one day on 23 January and should consequently be corrected from this date [11]. Similarly, the ECDC dataset manifested the same systematic measurement error.

This distortion was judged that it needs correction because, as mentioned, it is common to use the date attribute and country codes to create a primary key for these kinds of datasets. Furthermore, the exact report dates were essential to evaluate the outcomes of policy interventions and the effectiveness of public health measures, to reduce the disease severity. In this regard, even a small error in the date of clinical reports can change the clinical data analysis explanations and results and might wrongly inform decision makers [11].

\section{ORDER DEPENDENCIES VIOLATION}

During the analysis of cumulative time series, it was noticed that there are order dependencies violations in these datasets where it is known that the cumulative number of cases or deaths of the subsequent date cannot be less than the cumulative number of the previous day. Obviously, the time series in Figure 4 violates the Order Dependencies. 


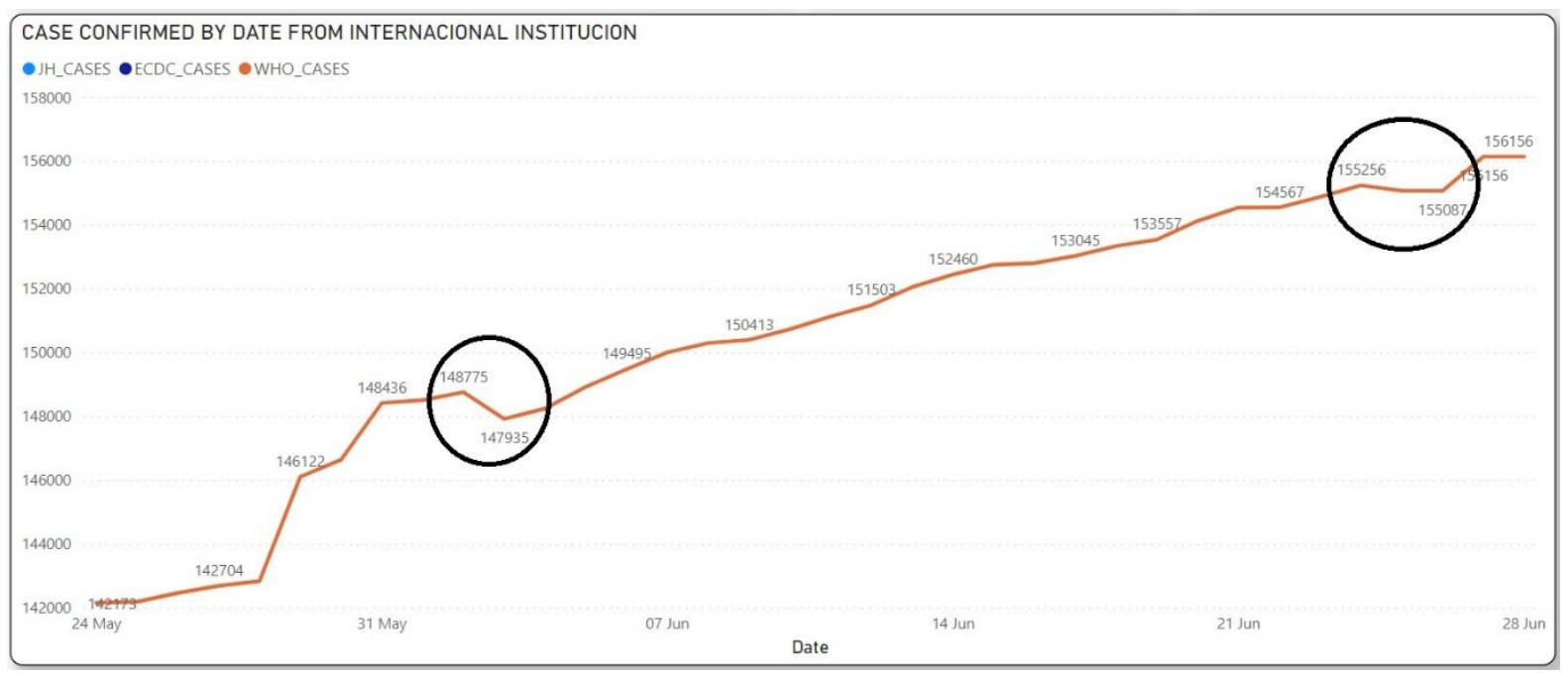

Figure 4. Order dependency violation.

\section{ABNORMAL DATA POINT OR DATA PERIOD}

As it was explained in the previous section, a single abnormal point refers to the situation where there is one day of an abrupt increase in the cumulative time series. This can have multiple causes, like the result of a large batch of tests was released or the change of reporting standard, e.g., some states started to report probable cases from a specific date.

Sometimes, we may experience a continuous abnormal period, referred to as the period where the increasing speed is significantly different from the previous and the subsequent period. Such an example has been shown in Figure 5.

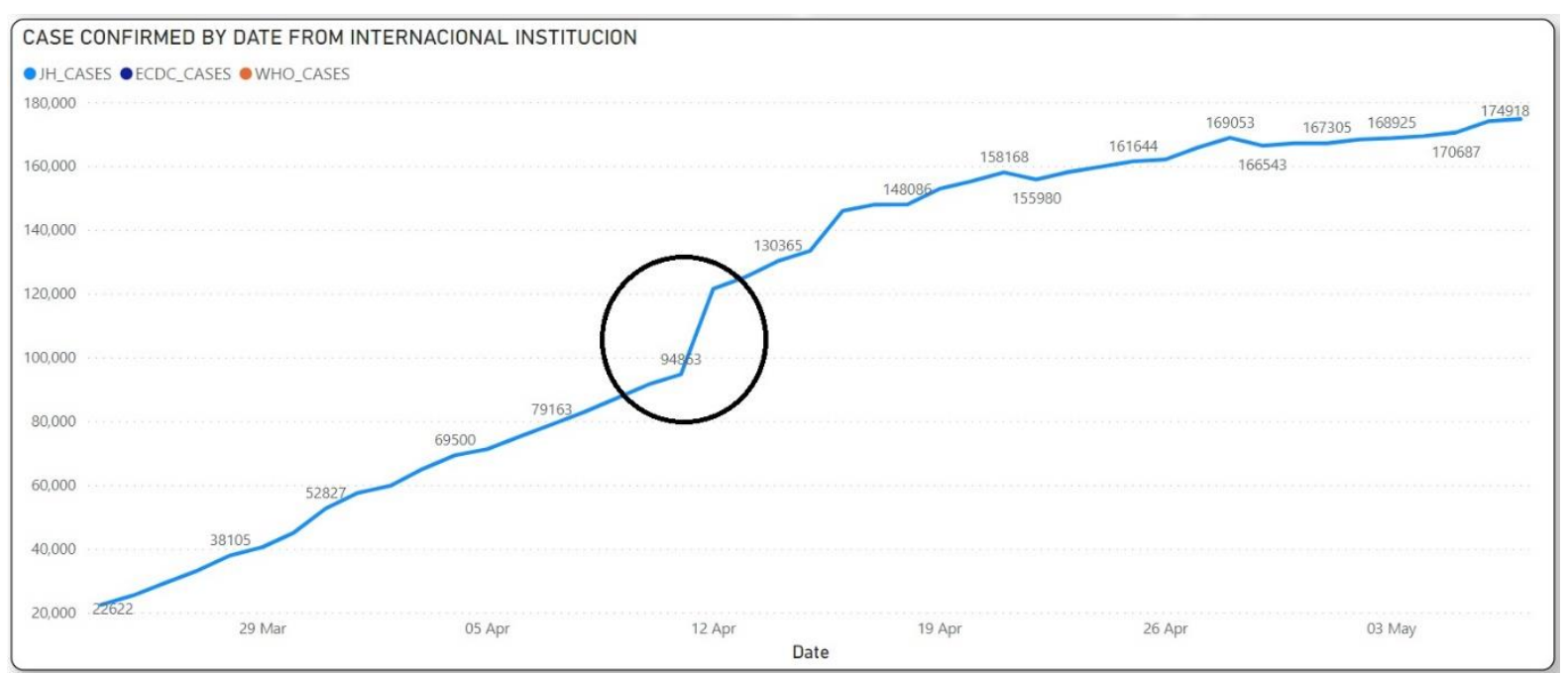

Figure 5: Single abnormal point. 


\section{COMPARATIVE ANALYSIS OF NIPHK, WHO, JHU, ECDC DATASETS}

As we know, the National Institute of Public Health of Kosovo (NIPHK) publishes accurate data of cumulative cases of new infections with COVID-19 as well as cumulative cases of deaths every day. Then we analyzed and compared the data obtained from NIPHK as a reference dataset with data from WHO, ECDC and JHU datasets for Kosovo reported cases. In the following figure (Figure 6), we can notice a large difference in cumulative case numbers between the cases reported by the NIPHK and the cases collected in the WHO, JHU and ECDC datasets.

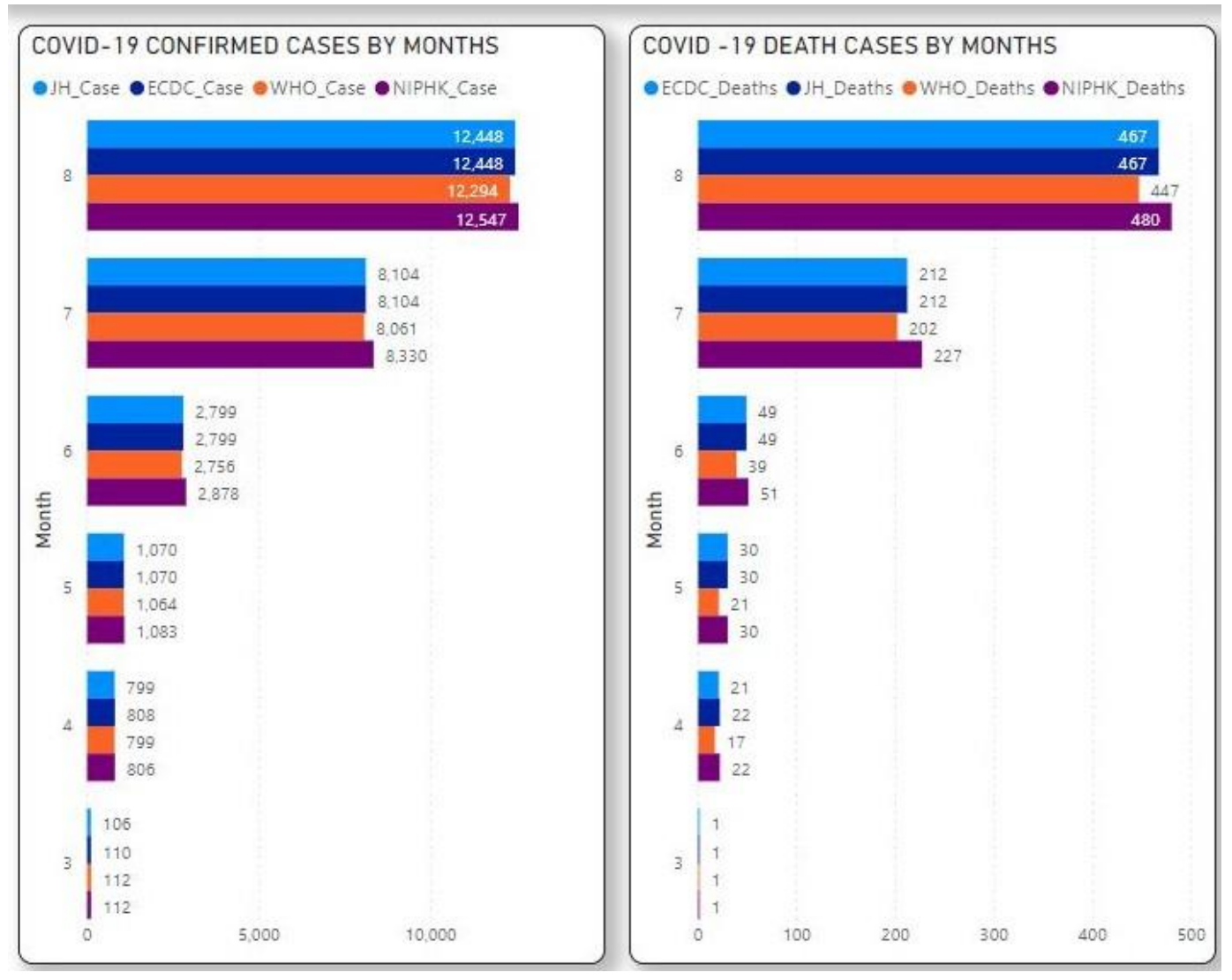

Figure 6: Cumulative case numbers from NIPHK, WHO, JHU, ECDC.

Figure 7 below shows the difference in cumulative cases compared day by day between NIPHK and WHO, JHU and ECDC, where it results that there are lot of mismatches between these datasets for cumulative cases of Republic of Kosovo. 


\begin{tabular}{|c|c|c|c|c|c|c|c|c|}
\hline - Date & JH_CASE & ECDC_CASE & WHO_CASE & NIPHK_CASE & NIPHK vs. ECDC & NIPHK vs, JH & NIPHKVS. WHO & \\
\hline $31 / 07 / 2020$ & 8,104 & 8,104 & 8,061 & 8,330 & $\otimes$ & $\otimes$ & $\otimes$ & \\
\hline $01 / 08 / 2020$ & 8,104 & 8,104 & 8,287 & 8,554 & $\otimes$ & $\otimes$ & 2 & \\
\hline $02 / 08 / 2020$ & 8,799 & 8,104 & 8,511 & 8,799 & 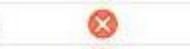 & 0 & $\otimes$ & \\
\hline $03 / 08 / 2020$ & 9,049 & 8,799 & 8,756 & 9,049 & 8 & 0 & 2 & \\
\hline $04 / 08 / 2020$ & 9,274 & 9,049 & 9,006 & 9,274 & $\otimes$ & (2) & (2) & \\
\hline $05 / 08 / 2020$ & 9,274 & 9,274 & 9,231 & 9,492 & 8 & 2 & $\otimes$ & \\
\hline $06 / 08 / 2020$ & 9,688 & 9,274 & 9,449 & 9,688 & (2) & 8 & 2 & \\
\hline $07 / 08 / 2020$ & 9,869 & 9,688 & 9,645 & 9,869 & 2 & 0 & 8 & \\
\hline $08 / 08 / 2020$ & 9,869 & 9,869 & 9,826 & 10,059 & $\otimes$ & 8 & 2 & \\
\hline $09 / 08 / 2020$ & 9,869 & 9,869 & 10,016 & 10,247 & (2) & 8 & (2) & \\
\hline $10 / 08 / 2020$ & 10,419 & 10,016 & 10,204 & 10,419 & $\otimes$ & 0 & (2) & \\
\hline $11 / 08 / 2020$ & 10,419 & 10,419 & 10,376 & 10,590 & 2 & $\otimes$ & $\otimes$ & \\
\hline $12 / 08 / 2020$ & 10,419 & 10,419 & 10,547 & 10,795 & 8 & $\otimes$ & 8 & \\
\hline $13 / 08 / 2020$ & 10,795 & 10,419 & 10,752 & 10,988 & $\otimes$ & 8 & 8 & \\
\hline $14 / 08 / 2020$ & 11,130 & 10,795 & 10,945 & 11,130 & $\otimes$ & 0 & 8 & \\
\hline $15 / 08 / 2020$ & 11,275 & 11,130 & 11,087 & 11,275 & 2 & (2) & (2) & \\
\hline $16 / 08 / 2020$ & 11,275 & 11,275 & 11,232 & 11,416 & 2 & 2 & (2) & \\
\hline $17 / 08 / 2020$ & 11,275 & 11,275 & 11,373 & 11,545 & 8 & $\otimes$ & 8 & \\
\hline $18 / 08 / 2020$ & 11,545 & 11,373 & 11,502 & 11,686 & $\otimes$ & $\otimes$ & 8 & \\
\hline $19 / 08 / 2020$ & 11,545 & 11,545 & 11,643 & 11,848 & (2) & 2 & 2 & \\
\hline $20 / 08 / 2020$ & 11,545 & 11,545 & 11,805 & 12,006 & (2) & 8 & 2 & \\
\hline $21 / 08 / 2020$ & 12,168 & 11,545 & 11,963 & 12,168 & $\otimes$ & 8 & 8 & \\
\hline $22 / 08 / 2020$ & 12,168 & 12,168 & 12,125 & 12,337 & 2 & $\otimes$ & (2) & \\
\hline $23 / 08 / 2020$ & 12,448 & 12,168 & 12,294 & 12,448 & (2) & (2) & 8 & \\
\hline
\end{tabular}

Figure 7: Mismatches between NIPHK, WHO, JHU and ECDC.

\section{COMPARATIVE ANALYSIS OF GRNM, WHO, JHU, ECDC DATASETS}

GRNM publishes accurate data of cumulative cases of new infections with COVID-19 as well as cumulative cases of deaths every day. We analyzed and compared the data obtained from GRNM as a reference dataset with data from WHO, ECDC and JHU datasets for North Macedonia reported cases. In Figure 8 below, we can notice a large difference in cumulative case numbers between the cases reported by the GRNM and the cases collected in the WHO, JHU and ECDC datasets. 


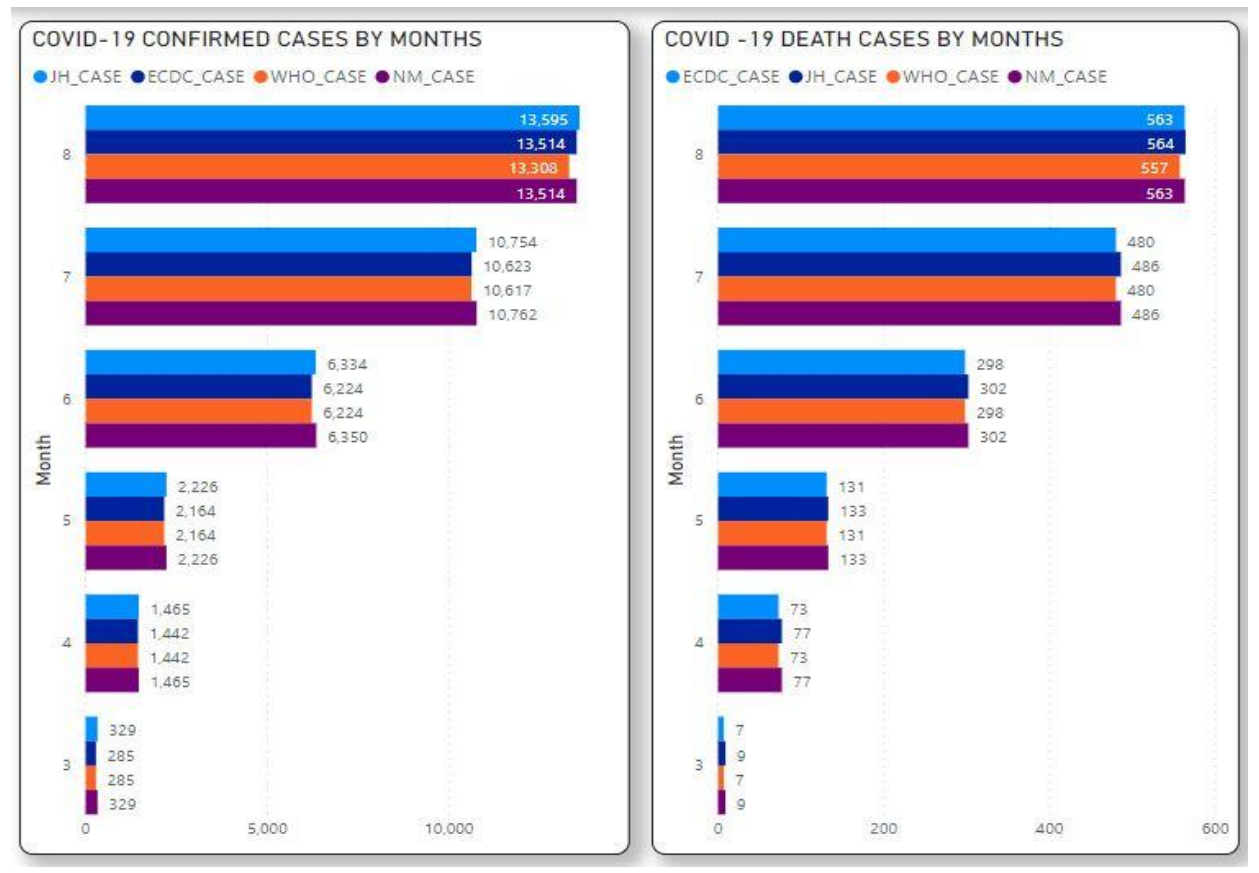

Figure 8: Cumulative case numbers from GRNM, WHO, JHU, ECDC.

Figure 9 below shows the difference in cumulative cases compared day by day between GRNM and $\mathrm{WHO}, \mathrm{JHU}$ and ECDC, where it results that there are a lot of mismatches between these datasets for cumulative cases of Republic of North Macedonia.

\begin{tabular}{|c|c|c|c|c|c|c|c|}
\hline ـ Date & JH_CASE & ECDC_CASE & WHO_CASE & NM_CASE & NM vs. ECDC & NM vs. JH & NM vs. WHO \\
\hline $16 / 05 / 2020$ & 1,762 & 1,740 & 1,740 & 1,762 & 8 & 0 & 2 \\
\hline $17 / 05 / 2020$ & 1,792 & 1,762 & 1,762 & 1,792 & 8 & (8) & 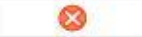 \\
\hline $18 / 05 / 2020$ & 1,817 & 1,792 & 1,792 & 1,817 & $\otimes$ & (8) & (2) \\
\hline $19 / 05 / 2020$ & 1,839 & 1,817 & 1,817 & 1,839 & $\otimes$ & $\theta$ & 8 \\
\hline $20 / 05 / 2020$ & 1,858 & 1,839 & 1,839 & 1,858 & 8 & $\theta$ & (2) \\
\hline $21 / 05 / 2020$ & 1,898 & 1,858 & 1,858 & 1,898 & 8 & $\theta$ & (2) \\
\hline $22 / 05 / 2020$ & 1,921 & 1,898 & 1,898 & 1,921 & 8 & Q & (8) \\
\hline $23 / 05 / 2020$ & 1,941 & 1,921 & 1,921 & 1,941 & 2 & (2) & 8 \\
\hline $24 / 05 / 2020$ & 1,978 & 1,941 & 1,941 & 1,978 & 8 & 0 & (2) \\
\hline $25 / 05 / 2020$ & 1,999 & 1,978 & 1,978 & 1,999 & $\theta$ & 0 & (2) \\
\hline $26 / 05 / 2020$ & 2,014 & 1,999 & 1,999 & 2,015 & 8 & $\otimes$ & $\otimes$ \\
\hline $27 / 05 / 2020$ & 2,039 & 2,015 & 2,015 & 2,040 & 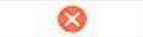 & $\otimes$ & $\otimes$ \\
\hline $28 / 05 / 2020$ & 2,077 & 2,040 & 2,040 & 2,078 & $\otimes$ & 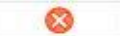 & (2) \\
\hline $29 / 05 / 2020$ & 2,129 & 2,078 & 2,078 & 2,129 & 8 & (2) & $\otimes$ \\
\hline $30 / 05 / 2020$ & 2,164 & 2,130 & 2,130 & 2,164 & $\otimes$ & $\theta$ & (2) \\
\hline $31 / 05 / 2020$ & 2,226 & 2,164 & 2,164 & 2,226 & 8 & (2) & 주 \\
\hline $01 / 06 / 2020$ & 2,315 & 2,226 & 2,226 & 2,315 & 8 & 0 & $\otimes$ \\
\hline $02 / 06 / 2020$ & 2,391 & 2,315 & 2,315 & 2,391 & 2 & $\theta$ & (2) \\
\hline $03 / 06 / 2020$ & 2,492 & 2,391 & 2,391 & 2,492 & $\otimes$ & 0 & (2) \\
\hline $04 / 06 / 2020$ & 2,611 & 2,492 & 2,492 & 2,612 & $\theta$ & $\otimes$ & 8 \\
\hline $05 / 06 / 2020$ & 2,790 & 2,612 & 2,612 & 2,792 & $\otimes$ & 8 & 2 \\
\hline $06 / 06 / 2020$ & 2,915 & 2,792 & 2,792 & 2,917 & (2) & $\otimes$ & (2) \\
\hline $07 / 06 / 2020$ & 3,025 & 2,917 & 2,915 & 3,028 & (2) & Q & $\otimes$ \\
\hline $08 / 06 / 2020$ & 3,152 & 3,028 & 3,028 & 3,155 & $\otimes$ & $\otimes$ & $\otimes$ \\
\hline $09 / 06 / 2020$ & 3,239 & 3,155 & 3,155 & 3,242 & $\otimes$ & ( & (2) \\
\hline
\end{tabular}

Figure 9: Mismatches between GRNM, WHO, JHU and ECDC. 


\section{CONCLUSION}

This study addressed some types of errors found out on three official datasets for COVID-19, currently used as the main references for researchers around the world and domain BI dashboards. Therefore, even minor errors in official COVID-19 datasets could significantly impact the various results for scientific purposes. This matter shows the importance of the accuracy, timeliness and completeness of COVID-19 official datasets for better scientific models and interpretations.

In order to compare these datasets, we converted them to a suitable format and then analyzed these data. We first detected abnormal data using Order Dependencies Violation, then we analyzed the weekend/holiday Delay Reports issue and identified abnormal data point or data period. To notice the differences in the data from the datasets of WHO, JHU and ECDC for cumulative deaths and cumulative cases for Kosovo and North Macedonia, through Power BI software, such figures have been presented that reflect all these differences.

Findings from this study, that reveal measurement errors in COVID-19 relevant datasets through the comparative cases for Republic of Kosovo and Republic of North Macedonia, could be used from the appointed institutions to improve their policies for data collection, design and output, as well as by scholars who might deepen their analysis on further work on the tolls as well as guidelines and frameworks for data improvements. 


\section{REFERENCES}

- John Hopkins University and Medicine, Coronavirus Resource Center, https://coronavirus.jhu.edu/, August 2020.

- $\quad \mathrm{Xu}, \mathrm{B}$. , et al., Open access epidemiological data from the COVID-19 outbreak. The Lancet Infectious Diseases, 2020.

- World Health Organization; Geneva, Switzerland: 2012. Framework and standards for country health information systems. Second edition.

- Varun Vasudevan, Abeynaya Gnanasekaran, Varsha Sankar, Siddarth A. Vasudevan, and James Zou:Disparity in the quality of COVID-19 data reporting across India,July 2020.

- World Health Organization. Geneva, Switzerland: Coronavirus disease, 2019 (COVID- 19) situation reports [Internet]. Available from https://www.who.int/emergencies/diseases/novelcoronavirus-2019/situation-reports/

- European center for disease prevention and control, Data on the geographic distribution of COVID-19 cases worldwide [Internet]. Available from:

https://www.ecdc.europa.eu/en/publications-data/download-todays-data-geographicdistribution-covid-19-cases-worldwide.

- The National Institute of Public Health of Kosovo, https://www.facebook.com/IKSHPK/, August 2020.

- The Government of the Republic of Northern Macedonia, https://koronavirus.gov.mk/stat

- G. Wang, Z. Gu, X. Li, S. Yu, M. Kim, Y. Wang, L. Gao, and L. Wang, "Comparing and integrating us COVID-19 daily data from multiple sources: A county-level dataset with local characteristics," arXiv preprint arXiv:2006.01333, 2020.

- Altieri, N., Barter, R. L., Duncan, J., Dwivedi, R., Kumbier, K., Li, X., Netzorg, R., Park, B., Singh, C., Tan, Y. S., et al. (2020), "Curating a COVID-19 data repository and forecasting county-level death counts in the United States,"arXiv preprint arXiv:2005.07882.

- Ashofteh A, Bravo JM. 2020. A study on the quality of novel coronavirus (COVID- 19) official datasets. Stat J IAOS. 36: 291-301. 